\title{
How can we judge a 'safe' dentist?
}

As if we needed reminding, recent events have served to underline once again how we in the UK are no longer an island in the sense that we are part of the complex global community, the constantly shifting sands of politics and economics. Dentistry has its own part to play. In previous editorials I have touched on both the issue of patients seeking dental care abroad and of the Department of Health recruiting overseas colleagues to help shore-up the number of dentists prepared to work in the NHS. As a slight sideline, it is a curious irony that certain states in Australia, for example, are now actively recruiting in the UK for dentists to emigrate there. The international ebb and flow of dentists seems to know no limits.

The matter does have other dimensions though, as the law requires us to consider how to judge a 'safe' dentist whose qualification originates outside the EEA. That is, the onus is on the General Dental Council (GDC) to do this in its role of protecting the public. As we know, in order to practise in the UK a dentist must be registered with the GDC and currently, overseas (nonEEA) dentists are required to pass the International Qualifying Examination (IQE) to be eligible to gain full registration and practise dentistry unsupervised in the UK. European Law requires that EEA citizens with appropriate EEA qualifications are automatically entitled to registration, while those with qualifications from outside of the EEA are entitled to have their qualifications and experience assessed on paper, and so may not be required to take an examination.

In order to keep up-to-date on modern techniques in assessment the GDC now feels that the IEQ may requiring changes and so is proposing a new examination instead. ${ }^{1}$ The streamlined examination would differ significantly from the current IQE, to include an Objective Structured Clinical Examination and stateof-the-art tests on dental manikins to assess clinical skills and ability to perform practical procedures. The purpose is to ensure that those who are successful in the assessment are fit to practise unsupervised dentistry and the GDC are at pains to point out that, "the purpose of an assessment is not to bar safe dentists from being admitted to the register". Which is a somewhat clumsy way of saying that it is not their role to alter the standard of the examination in order to be selective about those joining the register.
Of particular interest though is that the document acknowledges the difficulty in assessing, in an examination, certain attributes that are essential for dentists, such as the need to show integrity, honesty and trustworthiness. However, it does concede that a pre-examination language requirement is still necessary, since proficiency in communication is essential in being able to provide satisfactory care for patients. It suggests that the assessment of such attributes could be captured in three ways:

- Revalidation - in the future, registered dentists will need to prove on a regular basis that they are fit to remain registered;

- A pre-registration year perhaps for all newly-qualified dentists (including those who have just passed the IQE or equivalent examination);

- Extension of temporary registration - the successful examination candidate would only gain full registration after a period of supervised practice.

However, under the current Dentists' Act, it is not possible to implement a pre-registration year or extend the system of temporary registration without changes to primary legislation, which take a long time to implement.

All this serves to emphasise how complex the business is of trying to protect the public and of attempting to assess a 'safe' dentist. Whereas only a few years ago a primary qualification enabled one to practise for life without further checks, the future will clearly be increasingly bound up with assessments, verifications and evaluations. While this is obviously in the interests of the public and of standards, it does raise the question of GDC resources and thereby the level of the annual retention fee. Plus, one other, not insignificant question. Since the end of last month the Council has been registering new categories of Dental Care Professionals. So in future there will also be a need to screen for 'safe dental nurses', 'safe dental technicians', ‘safe...

\section{Stephen Hancocks OBE, Editor in Chief doi: $10.1038 /$ sj.bdj.4813966}

1. A consultation document is available on the GDC website (http://www.gdc-uk.org/ News+publications+and+events/Publications) on which comments are invited until 5 October 2006. 